\title{
Key Factors Affecting the B2B E-Commerce Evaluation and Outsourcing Practices in Australian and Taiwanese Hospitals
}

\author{
Chad Lin \\ Centre for Behavioural Research in Cancer Control, Curtin University \\ Curtin Health Research Campus, 10 Selby Street, Shenton Park, WA 6008, Australia \\ elin123au@yahoo.com.au \\ Yu-An Huang \\ Department of International Business Studies, National Chi Nan University \\ 470, University Road, Puli, Nantou 545, Taiwan \\ yahuang788@gmail.com
}

\begin{abstract}
In recent years, hospitals around the world have started to invest more heavily in business-to-business (B2B) electronic commerce (e-commerce) in an attempt to control their escalating operating costs as well as to maximize their revenue. However, relatively little research has been conducted to examine how hospitals evaluate their B2B e-commerce investments and to what extent their B2B e-commerce benefits are realized. To remain competitive, hospitals must also enhance and maintain their IT/B2B e-commerce systems through both internal and non-internal sourcing activities. Hence, we take a multi-case study approach to investigate the practices and processes of B2B ecommerce evaluation and benefits realization and their relationships with outsourcing and various organizational factors in Australian and Taiwanese hospitals. The findings suggest that a significant proportion of the Australian and Taiwanese hospitals had used a formal or semi-formal IT/B2B investment evaluation methodology or process to evaluate their B2B investments. A key contribution of this study is the identification and examination of key B2B e-commerce investment evaluation and outsourcing practices issues and challenges faced by the Australian and Taiwanese hospitals.
\end{abstract}

Keywords: healthcare, B2B e-commerce, hospitals, investment evaluation, benefits realization.

\section{Introduction}

Business-to-business (B2B) electronic commerce (ecommerce) technologies have gained strategic importance globally in the last decade and have outpaced all other forms of e-commerce. There is a potential for hospitals and other healthcare organizations to adopt and utilize B2B e-commerce technologies to assist in procuring medicines and other medical-related supplies and ingredients from pharmaceutical companies and other healthcare organizations. For example, the use of e-commerce technologies in conjunction with video-conferencing equipment enables hospitals and other healthcare organizations to procure their products more effectively and efficiently via online detailing with pharmaceutical companies. $^{1,2}$

However, the issue of realization of B2B ecommerce benefits has generated a significant amount of debate in the IT literature among the researchers, academics, and practitioners ${ }^{3}$. Some researchers (e.g. See Refs. 3-5) take the position that the confusion over the realization of IT/B2B e-commerce benefits is due to, 
among other things, lack of use of IT evaluation methodology to ensure successful evaluation of IT. In addition, despite the focus by recent literature of the role played by IT evaluation on realization of B2B ecommerce benefits, the importance of other organizational factors (e.g. information requirements determination, organizational IT infrastructure and capabilities, mutual strategic alignment and cultural similarity, and environmental uncertainty) and IT evaluation methodology adoption on B2B e-commerce benefits remain unclear. ${ }^{4}$

To remain competitive, hospitals must enhance and maintain their IT/B2B systems through both internal and non-internal sourcing activities. Hence, the management of outsourcing contracts has become one of the top key management issues for hospitals executives in recent years. However, difficulty in monitoring the performance of the outsourcing contracts is one of the major problems for hospitals. Despite the benefits of $\mathrm{B} 2 \mathrm{~B}$, organizations need to evaluate to determine whether their outsourcing efforts are paying off. ${ }^{6}$ Although the effective leverage and evaluation of B2B investments can result in improved organizational performance, ${ }^{7}$ there is little doubt that the less precisely bounded environment of B2B technology adds more complexity to the traditional IT measurement problem as this type of investment is physically distributed between suppliers and vendors, making the evaluation process even more difficult. ${ }^{8,9}$

The problem becomes more evident as B2B is used to link the supply chain or to change the structure of industries, since costs and benefits have to be tracked across functional and organizational boundaries. ${ }^{10,11}$ Existing business approaches are unequal to this task and planning for such systems has to encompass capabilities for managing and evaluating organizational capabilities to create value across the network of alliances and hence requires evolutionary approaches which can be tailored to business and information needs at different stages of organizational IT infrastructure and capabilities. ${ }^{8}$ Needless to say, many organizations find these issues challenging and evaluation methodologies are required to measure and monitor the performance of such investments, especially in terms of organizational factors such as user information requirements determination, strategic alignment and cultural similarities, and environmental uncertainty. $12,13,14$
There has not been much discussion in the literature with respect to the relationship between these organizational factors on B2B e-commerce evaluation and outsourcing. In particular, the practices and processes of B2B e-commerce evaluation and benefits realization in Australian and Taiwanese hospitals remain poorly understood and relatively underresearched. Therefore, the case study approach is conducted to investigate the evaluation practices of B2B investments in Australian and Taiwanese hospitals.

\section{Background}

The socio-technical systems theory (STS) was drawn in this study to the identified issues and problems emerged from the analysis of the case study data. The sociotechnical systems theory examines the introduction of innovations (e.g. B2B and IT outsourcing) into organizations from both the social and technical subsystems. ${ }^{15}$ The theory allows organizations to understand why results are meaningful and how the integration of the social and technical systems leads to improved results. ${ }^{16}$ STS has particular relevance to understand hospitals where social and technical issues have been identified as some of the key issues and problems in the implementation of B2B projects. ${ }^{17}$ The theory provides the foundation for an investigation of the organizational, social, and technological perspectives (e.g. B2B/IT investment evaluation, $\mathrm{B} 2 \mathrm{~B} / \mathrm{IT}$ outsourcing, user information requirements determination, organizational IT infrastructure and capabilities, environmental uncertainty, and strategic alignment and cultural similarity) that might affect the implementation of $\mathrm{B} 2 \mathrm{~B}$ and outsourcing projects in hospitals.

\subsection{Business-To-Business Electronic Commerce}

B2B e-commerce involves with Internet-based commercial activities between two or more different companies or organizations. ${ }^{18,19}$ The main characteristics of $\mathrm{B} 2 \mathrm{~B}$ e-commerce include: externalities and exponential growth; critical mass; customer cohesion; content and category depth; broadening and deepening hub services; and disintermediation. ${ }^{20}$ It is able to assist organizations in lowering the cost of entry and in expanding the market reach for a variety of business activities. The innovative B2B e-commerce as an Internet-based option provides a means of achieving the desired degree of 
interconnectivity without a huge investment and greater technical complexity. ${ }^{21}$ Its implementation allows business partners to access their internal business systems via the Internet. ${ }^{22}$ B2B e-commerce provides an efficient and effective channel for information exchange and sharing and enables organizations to trade on a $24 \times 7 \times 365$ basis. $^{22,23}$ It also helps organizations to use it as a wide-coverage, high-functionality, low-cost tool for venturing into new markets in the global economy. ${ }^{24,25}$

Despite all these benefits, organizations need to evaluate to determine whether their B2B efforts are paying off. ${ }^{6,26}$ Although the effective leverage and evaluation of B2B e-commerce investments can result in improved organizational performance, ${ }^{7}$ there is little doubt that the less precisely bounded environment of B2B technology adds more complexity to the traditional IT measurement problem as this type of investment is physically distributed between suppliers and vendors, making the evaluation process even more difficult. ${ }^{9}$ The problem becomes more evident as $\mathrm{B} 2 \mathrm{~B}$ e-commerce is used to link the supply chain or to change the structure of industries, since costs and benefits have to be tracked across functional and organizational boundaries. ${ }^{10,27}$ Existing business models are unequal to this task and planning for such systems has to encompass capabilities for managing and evaluating organizational capabilities to create value across the network of alliances and hence requires evolutionary approaches which can be tailored to business needs at different stages of organizational maturity. ${ }^{8}$ Needless to say, many organizations find these issues challenging and evaluation methodologies are required to measure and monitor the performance of such investments. ${ }^{28}$

\subsection{Business-To-Business Electronic Commerce Investment Evaluation Processes}

The difficulties in evaluating benefits are often the cause for uncertainty about the expected benefits of IT investment. $^{29}$ In addition, organizations have come to realize that it is increasingly difficult to justify the costs surrounding the procurement, development and adoption of IT investments such as B2B e-commerce., ${ }^{7,30}$ Hence, evaluation is often ignored or carried out inefficiently or ineffectively because of its elusive and complex nature. ${ }^{31,32}$ In fact, very few companies can consistently state that their IT investment is indeed value for money..$^{33,34}$ There are many methodologies that can be used to evaluate IT and B2B e-commerce investments. Some of the most widely recognized methodologies are: Information Economics Approach ${ }^{35}$; Kobler Unit Framework ${ }^{36}$; Multi-object, Multi-criteria Methods $^{37}$; and SESAME ${ }^{38}$. While IT/B2B investment evaluation processes are important for organizations, they are still insufficient in terms of ensuring that the benefits required are realized and delivered to the organization. ${ }^{39,40,41}$ Assessing the effective delivery of useful benefits from these services to the business is very difficult. According to Ward et al. ${ }^{42}$ (p215), the essence of benefits realization is "not to make good forecasts but to make them come true....... and IS/IT on its own does not deliver benefits." Benefits realization comprises of a range of management activities designed to ensure that an organization realized the benefits it plans to achieve from an IT investment. ${ }^{43}$ Benefits may be considered as the effect of the changes, i.e. management of changes - the difference between the current and proposed way that work is done. ${ }^{41}$

It has been found that there is a clear indication of the benefits that flow from being able to compare the impacts of a specific IT investment against a set of underlying objectives with the possibility of introducing corrective action (e.g. post-implementation review) if necessary. ${ }^{44}$ Earl $^{45}$ has also taken the view that benefits are associated with business change and not the technology itself. Things only get better when people start doing things differently. ${ }^{46}$ More recent B2B/IT evaluation studies in healthcare have begun to also examine the aspects of human/organizational and business processes which involve various stakeholders such as system developers, IT professionals, patients, medical professionals, and system users. ${ }^{47,48} \mathrm{~A}$ good evaluation of B2B/IT can help healthcare organizations and hospitals to, for example, improve quality of their systems, achieve greater clinical efficiency, reduce operating costs, improve the quality of care and effectiveness of the health information systems, and investigate $\mathrm{B} 2 \mathrm{~B} / \mathrm{IT}$ failures and learn from previous mistakes. ${ }^{49,50}$

However, evaluation is often not carried out effectively by healthcare organizations and hospitals. ${ }^{48,51}$ As a result, hospitals are under increasing pressure to find a way to evaluate the contribution of their B2B/IT to business performance, as well as to find reliable ways to ensure that the business benefits from $\mathrm{B} 2 \mathrm{~B} / \mathrm{IT}$ are actually realized. ${ }^{52}$ Therefore, the selection 
of a formal B2B/IT evaluation methodology or process which a hospital can implement is crucial in improving its performance. $^{53}$ In addition, obtaining users' acceptance and their information requirements of the new and/or outsourced B2B/IT evaluation can be instrumental in enhancing business performance. ${ }^{48,54}$

\subsection{Business-To-Business Electronic Commerce Outsourcing}

Despite the fact that many believe that extensive outsourcing by healthcare organizations and hospitals assists in creating an outsourcing market and culture that other healthcare organizations can tap into in meeting their requirements as well as in developing industry-wide standards and protocols among outsourcing contractors ${ }^{55}$, complexity and scope of B2B/IT outsourcing are often the major constraints and difficulties in evaluation and benefits realization processes. $^{42,44}$ One reason for this is that most organizations fail to properly monitor and evaluate their B2B/IT outsourcing contracts or projects. ${ }^{56,57}$ Indeed, most organizations do not have formal process to evaluate their B2B/IT outsourcing decision and, instead, relied on limited cost analysis associated with the outsourcing decision. ${ }^{58}$ Organizations that make extensive use of IT/B2B evaluation methodologies or measures have higher perceived payoffs. ${ }^{44}$ Misra $^{59}$ found that outsourcing organizations need to choose the evaluation methodologies which: (a) lead to the desired behavior by both outsourcing organizations and external outsourcing contractors; (b) are within the external outsourcing contractors' control; (c) can be easily measured by both the outsourcing organizations and external outsourcing contractors; (d) can be evaluated by objective criteria rather than subjective criteria; and (e) can be aligned with mutual strategic alignment, expectations, and business objectives.

Some of the many motivation and benefits contributing to the growth of the outsourcing in the healthcare industry include cost saving, improved customer satisfaction, focus of core competencies, reduction in staff turnover, access to requisite skills, improved services and efficiency, increased flexibility, and economies of scale. ${ }^{60,61,62,63,64,65}$ However, despite the promised savings and benefits from the B2B/IT outsourcing contracts, there have been risks and disadvantages for healthcare organizations to undertake outsourcing. These include employee resistance, poor strategic similarity between outsourcing hospitals and external outsourcing contractors, inability to manage outsourcing contracts, dependency on external outsourcing contractors, inexperienced employees by external contractors, hidden costs, and government regulations. ${ }^{61,66,67,68}$

\subsection{User Information Requirements Determination}

The information requirements determination (IRD) process is a critical phase within the SDLC. IRD has generated a lot of interest and debate among researchers and practitioners as a potential means for improving the success rates of ISD projects. ${ }^{13,54,69}$ The IRD process which Browne and Ramesh ${ }^{70}$ defined as "a set of activities used by a systems analyst when assessing the functionality required in a proposed system” (p. 625), has become increasingly important in obtaining the correct and complete set of user requirements. However, with today's rapid changes of technology and customer driven environments and needs, IRD have become increasingly difficult for systems analysts to elicit and predict. $^{71}$ There are two types of requirement uncertainty -requirements diversity and requirements instability. ${ }^{54}$ This IRD uncertainty can result in interpersonal conflict among stakeholders since system users desire changes to reflect environmental changes whereas IT professionals desperately need to lock-in requirements so that the project or contract can be delivered within budget and on time. ${ }^{54}$ This in turn can lead to poor project or contract performance. Hence, the successful IRD process during the ISD project is a critical factor for project or contract success.

A review of the relevant literature revealed that the IRD phase of an ISD project is a problematic process and in many cases, budget blowouts and missed deadlines occur. ${ }^{72,73}$ Too often, initial design and programming is followed by a reassessment of needs, redesign and then more programming. However, many ISD project failures have little to do with technical or programming issues. The source of many of these problems lies with one or a combination of the following factors: incomplete and/or inaccurate requirement specifications, lack of users' involvement, lack of flexibility of computer-based information systems, poor communication, worldviews of the systems analysts, lack of common knowledge, and lack of harmonious relationships between users and systems 
analysts. Incomplete and/or inaccurate requirements specifications can often lead an organization to address the wrong problem or identify the incorrect information needs and this may ultimately lead to IT/B2B project failures. $^{74}$ In this case, high levels of common knowledge and harmonious relationship between systems analysts and users can assist in obtaining complete user IRD which in turn can result in better project/contract performance. ${ }^{69}$

After all, the main reason why it was difficult to obtain accurate and complete user IRD is due to the constraints on humans as information processors and problem solvers. ${ }^{75}$ Finally, according to Browne and Ramesh ${ }^{70}$, the following challenges should be recognized by both systems analysts and users when they are dealing with each other: (a) there can never be a complete, correct set of user information requirements; (b) requirements are not stable over time, but are in a constant process of evolution; (c) the facilitation skills of systems analysts are crucial to the effective management of the IRD process; and (d) systems analysts work in a highly political contexts.

\subsection{Organizational IT Infrastructure and Capabilities}

Organizational IT infrastructure and capabilities is the organization's ability to effectively deploy IT infrastructure and capabilities towards the achievement of benefits such as competitive advantage in line with business goals. According to the literature, organizational growth with respect to the use of IT and the approach organizations take in the management and planning of information systems is conceived in terms of clearly defined stages of maturity. ${ }^{76}$ Various stages of growth models have been presented by researchers to describe the evolution of organizational information systems (e.g. See Refs.76-79). Despite some criticism of these models, they provide an insightful organizing framework for thinking about IT change in organizations. ${ }^{76}$ The Nolan stages of growth model of evolution related to organizational information systems is probably the most widely known and utilized model of this type. ${ }^{79}$ The model was designed to determine the effectiveness of an organization in utilizing IT to achieve its business goals. However, the Nolan model has attracted criticisms over the years. Nolan's own elaboration of the model over the years suggests that infrastructure and capabilities or maturity is not a static concept.

The revised stages of growth model by Galliers and Sutherland $^{76}$ is meant to overcome some of the limitations by introducing a means of bringing together a range of key elements associated with the operation and management of an organization generally. The revised model of Galliers and Sutherland ${ }^{76}$ can be represented as six stages, each with its particular set of conditions associated with the seven "S" elements. The seven elements are strategy, structure, systems, staff, style, skills, and superordinate goals. The six stages of the revised model of Galliers and Sutherland ${ }^{76}$ are: ad hocracy, starting the foundations, centralized dictatorship, democratic dialectic and cooperation, entrepreneurial opportunity, and integrated harmonious relationships. The revised model assessed the organization's ability to obtain business value from IT directly to its level of organizational infrastructure and capabilities or maturity and the results provided crucial information about the organization's ability to effectively utilize IT in order to achieve competitive advantage and business goals. The revised stages of growth model by Galliers and Sutherland ${ }^{76}$ was chosen as a useful framework to understand these practices in this study. In particular, the seven " $S$ " elements provided a rich set of conditions upon which we could analyze an organization's maturity, and by using these we were able to be confident about our benchmarking of the case study hospitals. Higher level of IT infrastructure and capabilities or maturity meant higher degree of organizational ability to address these seven elements.

\subsection{Strategic Alignment and Cultural Similarity}

The lack of strategic alignment between business and IT can have a great impact on the value of all IT outsourcing effort. ${ }^{57}$ Parker $^{80}$ has suggested that IT strategy should both derive from and shape business strategy in a dynamic environment. Strategic fit recognizes that both business and IT domains (i.e. "Business" and "Information Technology") should be managed and positioned in terms of their respective IT and business focuses. Functional integration focuses on the connection between strategy and execution and deals with the link: (1) between business strategy and IT strategy; and (2) between business operations and IT execution. The capabilities embedded in IT can open up 
additional possibilities for generating and delivering value to the organizations. Drawing upon the findings of the previous studies reviewed, Yayla and $\mathrm{Hu}^{81}$ have also found that organizations with higher levels of alignment of their strategies and control mechanisms perform better than those with lower levels of alignment. Such mutual alignment between outsourcing hospitals and external contractors can also assist in utilizing and integrating their various IT resources effectively to support their business strategies and to realize the maximum benefits of their outsourcing contracts. ${ }^{72,82}$ Organizations with a high IT strategic alignment have been found to exhibit better performance. ${ }^{12}$

The impact of culture similarity or divergence on organizational performance is an important research area for researchers. ${ }^{83,84}$ According to Hofstede ${ }^{85}$, the cultural divergence or distance between two entities with different cultures can be explained in terms of factors such as individualism/collectivism, masculinity/femininity, power distance, and uncertainty avoidance. Organizations from different cultures understand, and judge the nature of the world in systematically different ways. $^{86}$ Similarly, cultural differences between two organizations or countries can be significant as people (e.g. IT professionals and users) from different cultures understand and judge the nature of the world in systematically different ways. ${ }^{87}$ In the context of outsourcing, this can increase the costs of transaction, risks, and uncertainty since it is likely that external outsourcing contractors might not fully understand outsourcing hospitals' business culture or its needs. $^{86}$

\subsection{Environmental Uncertainty}

Environmental uncertainty refers to the degree of heterogeneity and dynamism among the environment and is among the primary sources of uncertainty for the organization. $^{88,89}$ Environmental uncertainty appears to be a critical dimension of an organization's environment and bearing on the degree of coordination required. ${ }^{14}$ It relates to the rate and pattern of changes in the organizational IT environments, including changes in end-user information needs, business processes, and organizational structures. ${ }^{14}$ In an organizational environment characterized by greater dynamism, managers must cope with rapid change of user requirements and uncertainty as well as to determine which are the best long-term IT and business processes to follow, in order to successfully coordinate and execute the required tasks within the organization. ${ }^{90,91}$ This is consistent with past literature that suggests that environmental uncertainty causes lack of information regarding the environmental factors associated with a given decision-making situation. ${ }^{92,93}$ Highly dynamic and variable environment lead to higher uncertainty and generate information processing needs. ${ }^{89,94}$ This would result in higher costs to monitor the information systems and to resolve potential problems which ultimately would affect the performance of the organizations. ${ }^{95,96}$

The review of the literature reveals that that higher level of environmental uncertainty requires more user involvement in processing information ${ }^{54}$ and demands more time and effort to manage information systems ${ }^{97}$. Increased environmental uncertainty may require greater coordination between multiple departments in order to execute the interdependent tasks. This is because environmental uncertainty consumes "more time, effort and energy" 97 (p. 618) and is "less amenable to managerial control" ${ }^{97}$ (p. 618) than stable environment. Traditionally, the effect of outsourcing on performance varies with the different levels of environmental uncertainty and the results are mixed. For example, Gilley and Rasheed $^{98}$ have found that stakeholder performance is positively related to peripheral outsourcing in a very stable environment. In contrast, McLellan et al. ${ }^{99}$ have found that IS managers claimed outsourcing was usually carried out to reduce risk and uncertainty. Uncertainty poses a risk to organizations and outsourcing provides an opportunity to mitigate the risk. Through outsourcing, managers seek to transfer this risk to the contractors as they are expected to have superior skills and resources to handle these risk factors. Hence, IS executives themselves need to be careful about the higher levels of environmental uncertainty which may result in higher information processing costs and therefore, affecting organizational performance and benefits. It is expected that the greater the environmental uncertainty, the more important it is more likely for organizations to undertake outsourcing in order to improve the performance and benefits of their information systems.

\section{Research Methodology}

The purpose of this study was to obtain an overview of B2B investment evaluation and benefits realization processes and practices in Australian and Taiwanese 
hospitals. The aim of this study is to provide evidence comparing Australia (a developed economy) and Taiwan (a newly industrialized economy) on evaluation and benefits realization practices of their B2B ecommerce investments. Case studies were conducted with IT managers, IT procurement managers or supply chain managers from 10 Australian hospitals and 10 Taiwanese hospitals, respectively. All of the hospitals interviewed had been using at least a B2B e-commerce system for more than five years and the most popular B2B e-commerce system used by the responding organizations was Electronic Data Interchange (EDI). In recent years, both Australian and Taiwanese hospitals have come to realize that they can only compete with competitors through the efficient use of their IT resources such as B2B e-commerce systems and health information systems. Hospitals executives in both countries are becoming increasingly aware of challenges and opportunities in order to be more efficient and effective in delivering healthcare services to their patients. To remain competitive, hospitals must enhance and maintain their IT/B2B e-commerce systems through both internal and non-internal sourcing activities. ${ }^{61}$

In Australia, hospitals' utilization of B2B ecommerce is generally lower than those in other industries such as retail and mining. This is despite the fact that there is a higher rate of human errors and failures in the procurement process within the hospitals. ${ }^{100}$ However, hospitals tend to on average overstocked by $30 \%$ of their total inventory. ${ }^{100}$ The proportion of Australian hospitals and other healthcare organizations that use the Internet to place orders is $44 \%$, and to receive orders is $11 \%$. The corresponding figures for other Australian industries are 46\% and 27\%, respectively. ${ }^{101}$ Driven by concerns about low ecommerce uptake and escalating procurement costs within the industry, several B2B e-commerce initiatives have been launched by Australian Federal and State governments during the last decade to develop better ways of, among other things, ordering and procuring medical supplies electronically within the Australian hospitals and healthcare industry (e.g. Project Electronic Commerce and Communication (PECC) and the Pharmaceutical Extranet Gateway (PEG) in 1998, ${ }^{102}$ the Monash Pharmacy Project under the Victorian Government's e-Commerce Exhibition Projects Program (ECEPP) in 2003, ${ }^{103}$ and GS1Locatenet GLN Directory for Healthcare in $2010^{104}$ ). These initiatives have attempted to assist in the integration of supply chain/B2B e-commerce functionality with other Australian hospital and healthcare IT systems. However, despite substantial amount of resources being spent by the Australian Federal and State governments, these initiatives have achieved only limited success so far.

In Taiwan, a universal National Health Insurance scheme was officially launched in 1995 to replace some 13 health insurance schemes that only covered $59 \%$ of its population. More than $97 \%$ of hospitals and healthcare providers in Taiwan are contracted with the Bureau of National Health Insurance (BNHI). Due to the financial difficulties within the national health care system in Taiwan, the costs and revenue of these hospitals and healthcare providers have been closely monitored by BNHI. ${ }^{105,106}$ BNHI's fixed-budget policy has resulted in reimbursement prices that made many hospitals unsustainable. That is, the payments to hospitals, have been decreasing markedly each year while, at the same time, their costs have been increasing rapidly. The reimbursement prices by the BNHI are among the lowest in the world. ${ }^{107}$ Under the twin pressures of BNHI reimbursement price constraints and the intense competition among hospitals, the total number of hospitals in Taiwan has decreased by more than 30\% (from 835 to 530) between 1986 and 2007. ${ }^{107,108}$

These twenty cases were deliberately chosen in order to focus efforts on theoretically useful cases (following the theoretical, non-random sampling strategy by Eisenhardt $^{109}$. The data collection at these twenty cases continued until a point of theoretical saturation, which is when the value of an additional interview was considered to be negligible. ${ }^{109}$ The case study method enabled the researcher to examine how both Australian and Taiwanese hospitals evaluated their B2B ecommerce investments and to what extent their B2B ecommerce benefits were realized. The questions asked during the interviews included the practices and processes of $\mathrm{B} 2 \mathrm{~B}$ e-commerce evaluation and benefits realization and their impact on $\mathrm{B} 2 \mathrm{~B}$ e-commerce benefits in Taiwanese hospitals, as well as other B2B ecommerce adoption and IT outsourcing issues. Multiple data sources were used and included hospital documents and annual reports. Extensive notes were taken during the interviews and they were later were coded and analyzed. This serves as a method of triangulation of research data and ensures that the questions and answers 
are properly understood by repeating or rephrasing the questions and through paraphrasing the responses back to the interview participants. ${ }^{110}$

In addition, qualitative content analysis by Miles and Huberman ${ }^{111}$ was then used to analyze the data from the case study. The analysis of the case study results was conducted in a cyclical manner and the results were checked by other experts in the field. The external experts were asked to trace the logical flow of the research study, research questions, case findings and analysis and identification of constructs and thereby identifying any gaps in the chain of evidence. ${ }^{112}$ The findings from these information gathering approaches were analyzed iteratively by the researchers on an individual level, differences reconciled and then a judgment made on each of the major themes. Questions relating to a particular research theme, for example, level of B2B e-commerce, were examined as a cluster. Divergent views within the same company were assessed in terms of the relative strength of the perspective according to the numbers of responses falling in particular categories. This was done as a form of in-case analysis and to develop general explanations and interpretations. ${ }^{109}$ These steps enhance the construct validity, reliability and overall quality of the research. ${ }^{112}$

Furthermore, the guidelines set out by Klein and Myers ${ }^{113}$ for conducting and evaluating interpretive case studies were also followed in an attempt to improve the quality of this research by minimizing some of the case study's main weaknesses. For example, the principle of multiple interpretations requires the researchers to be sensitive about the possible differences in interpretation among the participants. Therefore, seeking multiple sources of information within a research setting is an important characteristic of well-grounded research. In this research, multiple sources of information and data were sought for each case study. Where some participants' accounts did not reflect other participants' accounts or the researchers own observation and understanding, alternative explanations were sought from the participants themselves. The extensive notes were then re-examined and deeper interpretation of observation was produced.

\section{Research Findings}

Major Both participants from Australian and Taiwanese hospitals were asked about adoption and usage IT/B2B investment evaluation and benefits realization methodologies or processes for various B2B activities and revealed a reasonably high adoption of methodologies or processes for IT/B2B investment evaluation and IT/B2B benefits realization. For the participated Australian hospitals, $70 \%$ of them had used at least a formal or semi-formal IT/B2B investment evaluation methodology or process to evaluate their B2B investments whereas $60 \%$ had used a formal or semi-formal IT/B2B benefits realization methodology or process on their B2B investments. For Taiwanese hospitals, $80 \%$ of the participated hospitals had used at least a formal or semi-formal IT/B2B investment evaluation methodology or process to evaluate their B2B investments while only $40 \%$ had used a formal or semi-formal IT/B2B benefits realization methodology or process on their B2B investments. This showed that while the usage of IT/B2B investment evaluation methodology or process by Australian and Taiwanese hospitals was comparable, the usage of IT/B2B benefits realization methodology or process was significantly higher among the participated Australian hospitals.

The result was also interesting when compared with other cross-sectional IT evaluation studies carried out organizations in Australia, Taiwan, and UK. In general, Australian and Taiwanese hospitals interviewed in this study appeared to have higher adoption rates of IT/B2B investment evaluation and benefits realization methodologies or processes than their counterparts in other industries in these two countries. For example, the study conducted in Australian large organizations found that $66 \%$ and $33 \%$ had used an IT investment evaluation methodology and IT benefits realization methodology, respectively. $^{28}$ A survey conducted on large organizations in the UK by Ward et al. ${ }^{42}$ indicated that $60 \%$ and $12 \%$ of the organizations surveyed had adopted an IT investment evaluation methodology and IT benefits realization methodology, respectively. A more recent IT evaluation study conducted on Taiwanese small-medium enterprises (SMEs) revealed that $42 \%$ had used an IT investment evaluation methodology and a similar percentage of these SMEs (43\%) had adopted an IT benefits realization methodology or process. ${ }^{114}$ 
However, IT/B2B investment evaluation and benefits realization methodologies or processes were in most cases neither effective in ensuring successful IT/B2B systems nor they were widely used in both Australian and Taiwanese hospitals. In addition, most participating Australian and Taiwanese hospitals did not include intangible benefits in their B2B/IT investment appraisal and evaluation processes. Of those who had an IT/B2B benefits realization methodology or process, $100 \%$ also adopted an IT/B2B investment evaluation methodology or process. This is consistent with the survey by Lin and Pervan $^{28}$ in which $82 \%$ of organizations which had a benefits realization methodology also used an IT investment evaluation methodology. IT outsourcing was extremely popular among Australian and Taiwanese hospitals. All hospitals participated in this study had outsourced at least part of their IT functions. Most participated Australian and Taiwanese hospitals had also outsourced at least of part of their B2B e-commerce functions (60\% vs 70\%). Cost reduction and efficiency improvement were the two main reasons for both Australian and Taiwanese hospitals to outsource their B2B e-commerce functions. Moreover, most Australian and Taiwanese hospitals preferred those external IT outsourcing contractors which had a good track record and extensively skills and experience in healthcare outsourcing. However, the size of external IT outsourcing contractors was not an important selection factor for both Australian and Taiwanese hospitals. There were also differences for Australian and Taiwanese hospitals to undertake outsourcing. For Australian hospitals, outsourcing gave rise to greater business focus and increased justification of costs against often measurable business unit outcomes as well as to decrease the power of the union. For Taiwanese hospitals, outsourcing was often used as one way to overcome lack of resources and to downsize their labor force.

A number of issues emerged from the analysis of the text data in relation to this study.

\subsection{Lack of Accurate User Information Requirements Determination (IRD) Process}

As mentioned earlier, obtaining accurate and complete user IRD is one of the most critical aspects for a successful ISD process and most of the errors from the ISD can be traced back to the IRD stage. ${ }^{69,72}$ This is critical given that the main purpose of users engaging in the ISD process is to contribute their know-how and experience to determine actual requirements of the new systems and/or outsourcing contracts so that both users and developer requirements can be incorporated into the new system design. ${ }^{115}$ If key users and stakeholders are involved and updated during the outsourcing process, they may view the outsourced systems as their own systems. ${ }^{116}$ This can assist hospitals in, for example, communicating, sharing, and clarifying organizational and business objectives as well as in resolving issues arising from outsourcing contracts and projects. However, it appeared that few responding hospitals had paid sufficient attention to the potentially problematic user IRD process. For example, one IT procurement manager stated: “......It was difficult to obtain complete requirements from users......they were changing all the time......We couldn't do much about it.” In many cases, this had led to mismatch between user requirements and business outcomes from the IT/B2B outsourcing contracts since most of hospital know-how and experience integration process does not go through the established or documented procedures. One of the major reasons for this was that outsourcing hospitals often failed to allocate sufficient resources to properly manage and monitor the IRD process for their IT/B2B outsourcing contracts. Several other reasons were identified by the participants and the researchers: (1) outsourcing hospitals and external outsourcing contractors had conflicting agendas; (2) lack of effective communication between the top management of outsourcing hospitals and the users; (3) user requirements were not stable over time and kept changing; and (4) lack of experience of system analysts and developers to obtain accurate and complete user information requirements. In addition, many outsourcing hospitals and external outsourcing contractors simply did not allocate sufficient resources to set up a proper governance mechanism as well as to obtain sufficient competencies to manage and assess their IRD processes. To make the matter worse, many participating hospitals failed to involve users and stakeholders during the IT/B2B outsourcing contract process as well as to provide most current information to users in order to counter uncertainties (e.g. job loss and resistance to change) arising from the IT/B2B outsourcing contracts. 
It is not surprising that many potential problems were not properly identified before the commencement of the IT/B2B outsourcing contracts and the development of new IT/B2B systems. These had resulted in schedule delays, budget blowout, system flaws, and inappropriate design functions in later stages of the projects and contracts. Extra time and costs were often needed to undertake the remedial work to fix the system flaws and defects and in many cases, resulting in poor system and contract performance. However, there were differences for Australian and Taiwanese hospitals in engaging users and stakeholders during the IT/B2B outsourcing process. Australian hospitals executives tended to spend more time and allocate resources than their Taiwanese counterparts in involving and obtaining users requirements. For Australian hospitals, outsourcing gave rise to increased justification costs against measurable business unit outcomes. For Taiwanese hospitals, decision to outsource was often undertaken by the senior executives without consulting with the key users and stakeholders and was often used as one way to overcome lack of resources and to downsize their labor force.

\subsection{Insufficient Organizational IT Infrastructure and Capabilities}

Most of the outsourcing decisions were driven by poor organizational financial performance and therefore, not surprisingly, cost saving was by far the most often mentioned reason for organizations to undertake outsourcing in most studies. ${ }^{117,118}$ However, this study found that outsourcing hospitals generally did not take into account their level of organizational IT infrastructure and capabilities when making outsourcing decisions. The possession of sufficient level of organizational IT infrastructure and capabilities is crucial for outsourcing hospitals to develop a capability to effectively manage and engage their external outsourcing contractors. ${ }^{119}$ It was surprising that many hospitals did not adopt a formal strategy to improve its organizational IT infrastructure and capabilities although some had plans for providing limited training courses for users and executives to use the new systems when they are developed. However, the organizational IT infrastructure and capabilities to manage and engage external outsourcing contractors was only raised by those outsourcing hospitals which had disputes with their contractors during the contract management process.

Most participating outsourcing hospitals did not seem to have the sufficient level of organizational IT infrastructure and capabilities and IT staff to undertake the IT/B2B outsourcing contracts. Existing IT applications and business processes were not integrated well in most of the hospitals interviewed. This study examined participating outsourcing hospitals' organizational IT infrastructure and capabilities via IT infrastructure classification ${ }^{120}$ as well as the level of organizational IT maturity as described in the revised Stage of Growth Model. $^{76}$ Weill $^{120}$ classified IT infrastructure and capabilities into the following three components: (1) shared IT components, (2) IT human/management competence, and (3) shared technological services. Half of the Australian hospitals and $40 \%$ of Taiwanese hospitals interviewed indicated they had acquired appropriate and sufficient hardware and software to maintain and manage their outsourcing contracts and contractors. In terms of the IT human/management competence component, half of Australian hospitals interviewed revealed that they had possessed sufficient technical managerial skills and IT planning and management practices to manage their IT/B2B outsourcing contracts and contractors. However, only $30 \%$ of Taiwanese hospitals interviewed indicted that they had possessed sufficient technical managerial skills and IT planning and management practices to manage their IT/B2B outsourcing contracts and contractors. The reason behind this was that more Taiwanese hospitals also outsourced part of their IT management functions than their Australian counterparts. As a result, many Taiwanese hospitals did not possess sufficient IT human/management competence to manage and maintain their IT/B2B outsourcing contracts and contractors.

In terms of the shared technological services, most Australian and Taiwanese hospitals interviewed stated that their existing IT/B2B applications and business processes were not integrated well. Most participating hospitals did not possess appropriate shared set of IT applications and business processes to manage their outsourced IT/B2B systems. The results also showed a positive correlation between the hospitals which possessed higher level of organizational IT infrastructure and capabilities and the use of both IT/B2B investment evaluation and benefits realization 
methodologies and processes. In terms of their organizational IT maturity, the participating hospitals were also asked about where they thought their hospitals stand in terms of its stage of growth for each of the seven elements as described in Galliers and Sutherland's Stage of Growth Model. ${ }^{76}$ The results showed that the "average" hospitals were in stages 4 and 5 in most of the seven elements. Moreover, Australian hospitals appeared to have higher level of organizational IT maturity than Taiwanese hospitals as they had higher mean stages for all of the seven elements. Australian hospitals scored high points in terms of IT leadership style and superordinate goals while Taiwanese hospitals scored better in elements related to IT systems and superordinate goals. The results also demonstrated a positive association between the more mature hospitals (i.e. higher stages on the seven elements) and the use of both IT/B2B investment evaluation and benefits realization methodologies and processes. Other useful capabilities in engaging external outsourcing contractors mentioned by participating hospitals during the interviews included relationship building and contract monitoring and facilitation processes.

\subsection{Lack of Mutual Strategic Alignment and Expectations}

As mentioned earlier, organizations with higher levels of alignment of their strategies and control mechanisms perform better than those with lower levels of alignment. $^{81}$ Similarly, such mutual alignment between outsourcing hospitals and external contractors can also assist in utilizing and integrating their various IT resources effectively to support their business strategies and to realize the maximum benefits of their outsourcing contracts. ${ }^{72,82}$ However, most participating hospitals admitted that it was not easy to achieve such alignment. This was due to the fact that from the preproject justification stage an external outsourcing contractor had to be evaluated and then selected based on not only outsourcing hospital's organizational and service requirements but also areas of similarity in terms of its strategic alignment, visions, and expectation between both parties. One IT manager commented: "...... a lot of time and resources had been spent..... to make sure that our (outsourcing hospital and contractor's) strategies and control mechanism are properly aligned......" In other words, sufficient time and resources for a proper IT investment evaluation methodology or process had to be allocated at the preproject justification stage. Outsourcing hospitals also needed to communicate and agree to the strategic alignment, visions, and expectations with their external outsourcing contractors before the signing of the contracts. The lack of mutually agreed strategic alignment, visions, and expectation between the outsourcing hospitals and their contractors can often lead to unfulfilled goals and requirements for both parties. This can affect the quality and user satisfaction of the outsourced IT/B2B systems developed by the contractors. For Australian hospitals lack of funding was often the most mentioned reason for not achieving such alignment while for Taiwanese hospitals the number one reason was lack of expertise and time in conducting a properly IT investment evaluation at the pre-project justification stage to ensure that a contractor with similar strategic alignment was selected.

\subsection{Cultural Divergence between Outsourcing Hospitals and External Contractors}

Australian and Taiwanese hospitals participated in this study outsourced their IT/B2B systems to external outsourcing contractors in the hope to realize the benefits such as cost savings, higher service quality, and improved business efficiency. However, not all hospitals were able to realize these expected benefits due to cultural divergence or distance between the hospitals and the external outsourcing contractors. ${ }^{86}$ According to Hofstede ${ }^{85}$, the cultural divergence or distance between two entities with different cultures can be explained in terms of factors such as individualism/collectivism, power distance, and uncertainty avoidance. For example, based on the individualism-collectivism index proposed by Hofstede $^{85}$, Australia is an individualistic country whereas Taiwan represents a collectivistic country. Most western and individualistic cultures tend to perceive themselves as distinct from each other whereas many Asian countries are characterized by high collectivism. Asian countries with high collectivism usually focus more on community, society, or nation and are concerned with cohesion within the social group.

Taiwanese society is characterized by high collectivism, high uncertainty avoidance, and high power distance. This was particularly the issue for the 
Taiwanese hospitals where the entire Taiwanese IT outsourcing market was dominated by Western outsourcing companies. Organizations from different cultures understand, and judge the nature of the world in systematically different ways. ${ }^{86}$ Some of the problems encountered by both of the Taiwanese hospitals and their external outsourcing contractors related to the different shared values and methods of achieving and managing projects and goals. Although for Taiwanese hospitals to enter into IT/B2B outsourcing contracts with foreign contractors were likely to gain global synergies, this had also created a high degree of uncertainty for these outsourcing hospitals since the foreign outsourcing contractors may not fully understand their business culture and values. It was not surprising to find that there was often a cultural clash between the Taiwanese public hospitals in particular and their foreign external outsourcing contractors on their expectation of the outsourcing contracts. This was especially true for the Taiwanese public hospitals which expected better and efficient services in line with government regulations and directives. For example, an IT manager of a Taiwanese public hospital said: "As $a$ public hospital, the reason for outsourcing was often more to do with providing better services in line with government directives rather than simply cost saving and generating revenue......but our outsourcing contractor appears to be only interested in making money out of us from the outsourced .......system.......we also seem to have different cultures in managing things and achieving the stated goals..." In addition, the selection of right external outsourcing contractors was an important part of IT investment evaluation process for the Taiwanese hospitals to undertake. It came down to whether an outsourcing relationship worked best when the cultural distance between hospitals and outsourcing contractors was small. Those hospitals which did not undertake proper IT investment evaluation process at the pre-project stage on their outsourcing projects to determine the cultural distance between themselves and their external outsourcing contractors tended to have more cultural related issues after the contracts were signed. On the other hand, this was a lesser problem for the Australian hospitals where the Australian IT outsourcing market was dominated by domestic or foreign contractors owned by companies located in western countries. This smaller overall cultural distance was an important factor for Australian hospitals having less cultural related problems with their external outsourcing contractors.

\subsection{The Impact of Environmental Uncertainty}

High level of environmental uncertainty can cause business instability and errors which can result in a negative effect on business decision making process and performance. All participants interviewed agreed that environmental uncertainty is an important factor which can influence the investment evaluation of the organizational performance as well as the hospitals' relationships and trust with external outsourcing contractors. The results of the study indicated that there was indeed a significant impact of the environmental uncertainty on both Australian and Taiwanese hospitals. In some instances, the participants responded by trying to minimize instability by trying to manage changes carefully and by establishing better working relationships with their external outsourcing contractors. One IT supply chain manager revealed that: “......both the end users' information needs and business processes have changed rapidly and constantly in recent years....we just cannot keep up with these as we do not have enough manpower and time to manage these." Many participants complained that no proper training and procedures were put in place by hospital executives to assist them in dealing with the environmental uncertainty. Moreover, those hospitals which face higher level of environmental uncertainty were more responsive to their competitors. However, hospitals facing lower uncertainty were more responsive to the demands by their outsourcing contractors. In general, Taiwanese hospitals appeared to have coped better than their Australian counterparts in terms of changes in new leadership and strategic directions while Australian hospitals fared better with uncertainty in governmental policy and regulations.

\section{Discussions and Conclusion}

Case studies were conducted in both Australian and Taiwanese hospitals which had adopted and implemented B2B e-commerce systems. All interviewed hospitals had outsourced at least part of their IT functions, Due to cost and efficiency concerns, a significant proportion of Australian and Taiwanese hospitals (60\% vs $70 \%$ ) had contracted out at least one component of their B2B e-commerce systems. Having greater business focus was often one of the major 
reasons for Australian hospitals to outsource their B2B systems while for Taiwanese hospitals B2B outsourcing was often adopted to overcome lack of resources as well as to downsize their labor force. The findings also revealed that while a great proportion of the Australian and Taiwanese hospitals (70\% vs $80 \%$ ) had used a formal or semi-formal IT/B2B investment evaluation methodology or process to evaluate their B2B investments, the same cannot be said about their B2B benefits realization practices. About $60 \%$ of Australian hospitals had used a formal or semi-formal IT/B2B benefits realization methodology or process on their B2B investments and only $40 \%$ of Taiwanese hospitals had adopted the above-mentioned methodology or process. Of those who had adopted the methodologies or processes, most of them indicated that they were in most cases neither effective in ensuring successful IT/B2B systems nor they were widely used in these hospitals. These findings have the potential to assist hospitals and other healthcare organizations in enhancing the understanding of their IT/B2B ecommerce evaluation and benefits realization practices and processes. Paying close attention to their IT/B2B evaluation and benefits realization practices and processes is likely to enable hospitals and other healthcare organizations to reap benefits from their B2B e-commerce investments.

Other factors such as the level of organizational IT infrastructure, mutual strategic alignment and expectation between hospitals and external outsourcing contractors were critical in obtaining the higher level of organizational performance and benefits from the B2B e-commerce systems. It is imperative for the senior executives of the hospitals to carefully examine these factors in order to obtain expected B2B e-commerce benefits. However, this does not mean that other behavioral, attitudinal and organizational issues should be neglected. For example, understanding the reactions of their users toward the newly acquired B2B ecommerce systems and their subsequent behavior can assist hospital executives in devising the appropriate intervention strategies, policies, and programs to maximize their use and their effects on the hospitals. These deliberate steps must be identified to achieve desirable outcomes and increase the pace of IT/B2B ecommerce dissemination within the hospitals. For instance, relevant project champions should be identified to assist in minimizing the uncertainty of others in adopting new IT/B2B e-commerce investments.

Obtaining accurate and complete user IRD is one of the most critical aspects for a successful ISD process and most of the errors from the ISD can be traced back to the IRD stage. However, it appeared that few outsourcing hospitals had paid sufficient attention to the potentially problematic user IRD process. In addition, there were differences for Australian and Taiwanese hospitals in engaging users and stakeholders during the IT/B2B e-commerce outsourcing process. Australian hospitals executives tended to spend more time and allocate resources than their Taiwanese counterparts in involving and obtaining users requirements. In addition, cultural divergence was particularly the issue for the Taiwanese hospitals where the entire Taiwanese IT outsourcing market was dominated by Western outsourcing companies. Some of the problems encountered by both of the Taiwanese hospitals and their external outsourcing contractors related to the different shared values and methods of achieving and managing projects and goals. Although for Taiwanese hospitals to enter into IT/B2B e-commerce outsourcing contracts with foreign contractors were likely to gain global synergies, this had also created a high degree of uncertainty for these outsourcing hospitals since the foreign outsourcing contractors may not fully understand their business culture and values. On the other hand, this was a lesser problem for the Australian hospitals where the Australian IT outsourcing market was dominated by domestic or foreign contractors owned by companies located in western countries.

Moreover, most participating hospitals admitted that it was not easy to achieve alignment of their strategies and control mechanism with external contractors in terms of their outsourcing contracts. The lack of mutually agreed strategic alignment, visions, and expectation between the outsourcing hospitals and their contractors can often lead to unfulfilled goals and requirements for both parties. This can affect the quality and user satisfaction of the outsourced IT/B2B ecommerce systems developed by the contractors. For Australian hospitals lack of funding was often the most mentioned reason for not achieving such alignment while for Taiwanese hospitals the number one reason was lack of expertise and time in conducting a properly IT investment evaluation at the pre-project justification stage to ensure that a contractor with similar strategic 
alignment was selected. This study also found that outsourcing hospitals generally did not take into account their level of organizational IT infrastructure and capabilities when making outsourcing decisions. It was surprising that many hospitals did not adopt a formal strategy to improve its organizational IT infrastructure and capabilities although some had plans for providing limited training courses for users and executives to use the new systems when they are developed. In terms of organizational IT infrastructure and capabilities, Australian hospitals appeared to be more mature in terms of their IT than their Taiwanese counterparts.

The results of the study also indicated that high level of environmental uncertainty can cause business instability and errors which can result in a negative effect on business decision making process and performance. In some instances, the participants responded by trying to minimize instability by trying to manage changes carefully and by establishing better working relationships with their external outsourcing contractors. Those hospitals which face higher level of environmental uncertainty were more responsive to their competitors. However, hospitals facing lower uncertainty were more responsive to the demands by their outsourcing contractors. In general, Taiwanese hospitals appeared to have coped better than their Australian counterparts in terms of changes in new leadership and strategic directions while Australian hospitals fared better with uncertainty in governmental policy and regulations.

\section{Future Research Directions and Limitations}

Unlike many other industries, B2B e-commerce systems within the hospital industry are generally not mature enough. Due to the limited IT/B2B e-commerce sophistication between hospitals and other healthcare organizations, distributors, suppliers, and business partners in the past, they are lagging behind the bigger players in other industries in using B2B e-commerce applications to create competitive business networks. Despite this, B2B e-commerce systems and applications are creating a more level playing field for all industry players. It is expected that future B2B e-commerce systems and applications will bring about faster and more efficient business to hospitals by providing their users and patients more convenience and variety.
In the meantime, hospitals need to pay close attention to other potential B2B e-commerce system problems and issues such as lack of standardized B2B protocols and interoperability issues. Although industry/government-sponsored B2B protocols and standards do exist but they need to be improved in order for hospitals to better interact within and between multiple B2B e-commerce systems and applications. In addition, hospitals need not only to resolve the interoperability problems between their e-commerce systems and applications but also their ability to participate in multiple B2B e-commerce web portals. This issue will grow in importance in the near future as more and more B2B e-commerce systems and applications reach critical mass in not just the hospital and healthcare industry but also in other industries.

One limitation may be seen in the choice of identified organizational factors which may not fully capture the complex nature of the IT/B2B evaluation and outsourcing practices and in which hospitals operate. For example, there are different aspects of environmental uncertainty and each can play a different role in organizational performance and outcomes. There is a need to examine how each aspect of environmental uncertainty influences different aspects of managerial and organizational practices such as strategy formulation and decision-making processes. Moreover, the study involved only 20 hospitals in Australia and Taiwan and the findings are based on the Australian and Taiwanese contexts. It would be interesting to conduct the research in other countries and with different healthcare systems and applications. This research relied on the information provided at a particular point in time. Further research could take a longitudinal approach as the hospitals' B2B e-commerce investment evaluation and benefits realization practices and processes are likely to change over time. Alternatively, the study could be replicated in a few years' time to examine how IT/B2B e-commerce investment evaluation and benefits realization practices and processes in Australian and Taiwanese hospitals have changed and are being managed and evaluated in light of new or emerging B2B e-commerce technologies.

\section{References}

1. P. Guy and Gartenmann, T. Big Pharma can still find big value in E-health, Boston Consulting Group. Available 
www.bcg.com (2001).

2. J. Houghton Information Technology and the Revolution in Healthcare, Pharmaceutical Industry Project - Equity, Sustainability and Industry Development Working Paper Series No. 4, Centre for Strategic Economic Studies, Victoria University of Technology, Australia (2002).

3. E. Brynjolfsson and Hitt, L. M. Computing Productivity: Firm-Level Evidence, The Review of Economics and Statistics. 85(4), (2003) 793-808.

4. T.A. Byrd, Lewis, B.R., and Bryan, R.W. The Leveraging Influence of Strategic Alignment on IT Investment: An Empirical Examination. Information and Management, 43, (2006) 308-321.

5. Q. Hu and Quan, J. J. Evaluating the Impact of IT Investments on Productivity: A Causal Analysis at Industry Level. International Journal of Information Management, 5(1), (2005) 39-53.

6. M. Cutler and Sterne, J. (2000) E-Metrics: Business Metrics for the New Economy, NetGenesis, Source: [OnLine]: http://www.netgen.com/emetrics/.

7. N. Melville, Kraemer, K. and Gurbaxani, V. Review: Information Technology and Organizational Performance: An integrative Model of IT Business Value, MIS Quarterly, 28(2), (2004) 283-322.

8. C. Lin, Huang, Y. and Burn, J. Realising B2B eCommerce Benefits: The Link with IT Maturity, Evaluation Practices, and B2B e-Commerce Adoption Readiness, European Journal of Information Systems, 16(6), (2007) 806-819.

9. Y. Zhuang Does Electronic Business Create Value For Firms? An Organizational Innovation Perspective, Journal of Electronic Commerce Research, 6(2), (2005) 146-159.

10. A. Barua, Konana, P. and Whinston, A. B. An Empirical Investigation of Net-Enabled Business Value, MIS Quarterly, 28(4), (2004) 585-620.

11. Y. Liu and Lin, C. How Are Public Sector Organizations Assessing their IT Investments and Benefits - An Understanding of Issues For Benchmarking, International Journal of Advanced Information Technologies, 2(2), (2008) 86-100.
12. Y.E. Chan, Huff, S.L., Barclay, D.W., and Copeland, D.G. Business strategy orientation, Information Systems Research, 8(2), (1997). 125-150.

13. I. Wu and Shen, Y. A Model for Exploring the Impact of Purchasing Strategies on User Requirements determination of e-SRM, Information and Management, 43, (2006) 411-422.

14. W. Xia and Lee, G. Complexity of information systems development projects: conceptualization and measurement development, Journal of Management Information Systems, 22(1), (2005) 45-8.

15. E. H. Trist, Murray, B.J., and Pollack, A. Organizational Choice, Tavistock, London (1963).

16. A.B. Shani and Sena, J. A. Information technology and the integration of change: sociotechnical system approach, Journal of Applied Behavioral Science, 30(2), (1994) 247-261.

17. R. Heeks Information Systems and Developing Countries: Failure, Success and Local Improvisations. Information Society, 18(2), (2002) 101-112.

18. C. Standing and Lin, C. Organizational Evaluation of the Benefits, Constraints and Satisfaction with Business-ToBusiness Electronic Commerce, International Journal of Electronic Commerce, 11(3), (2007) 107-153.

19. F. Stehling and Moormann, J. Strategic Positioning of ECommerce Business Models in the Portfolio of Corporate Banking, Proceedings of the 35th Hawaii International Conference on System Sciences (2002).

20. Y. E. Zeng, Wen, H. J., and Yen, D. C. Customer Relationship Management (CRM) in Business-tobusiness (B2B) E-commerce, Information Management and Computer Security, 11(1), (2003) 39-44.

21. P.Y.K. Chau and Jim, C.C.F. Adoption of Electronic Data Interchange in Small and Medium Sized Enterprises. Journal of Global Information Management, 10(4), (2002) 61-85.

22. K.S. Lee, Lim, G. H. and Tan, S. J. Dealing with Resource Disadvantage: Generic Strategies for SMEs, Small Business Economics, 12(4), (1999) 299-311.

23. H. Tsao, Lin, K. H., and Lin, C. An Investigation of

Published by Atlantis Press

Copyright: the authors 
Critical Success Factors in the Adoption of B2BEC by Taiwanese Companies, The Journal of American Academy of Business, Cambridge, 5(1/2), (2004) 198-202.

24. C. Lin, Huang, Y., Jalleh, G., Liu, Y., and Tung, M. An Exploratory Study of Factors Affecting Adoption and Implementation of B2B E-Commerce in Australian Health Care Organizations, International Journal of Electronic Commerce Studies, 1(2), (2010) 77-96.

25. M.S. Raisinghani, Melemez, T., Zhou, L., Paslowski, C., Kikvidze, I., Taha, S., and Simons, K. E-Business Models in B2B: Process Based Categorization and Analysis of B2B Models, International Journal of EBusiness Research, 1(1), (2005) 16-36.

26. C. Lin, Huang, Y. and Stockdale, R. Developing a B2B Website Effectiveness Model for SMEs, Internet Research, (21)3, (2011) 304 - 325.

27. C. Lin, Lin, K., Huang, Y., and Jalleh, G. The Fit Between Organizational B2B E-commerce Policy, IT Maturity and Evaluation Practices on B2B E-commerce Performance in Australian Healthcare Organizations, African Journal of Business Management, 5(4), (2011) 1983-2005.

28. C. Lin and Pervan, G. The Practice of IS/IT Benefits Management in Large Australian Organizations, Information and Management, 41(1), (2003) 13-24.

29. T.J.W. Renkema and Berghout, E. W. Methodologies for Information Systems Investment Evaluation at the Proposal Stage: A Comparative Review, Information and Software Technology, 39, (1997) 1-13.

30. C. Lin, Huang, Y., and Tseng, S. A Study of Planning and Implementation Stages in Electronic Commerce Adoption and Evaluation: The Case of Australian SMEs, Contemporary Management Research, 3(1) (2007) 83100.

31. C. Lin, Huang, Y., and Cheng, M. The Adoption of IS/IT Investment Evaluation and Benefits Realization Methodologies in Service Organizations: IT Maturity Paths and Framework, Contemporary Management Research, 3(2), (2007) 173-194.

32. V. Serafeimidis and Smithson, S. The Management of Change for Information Systems Evaluation Practice:
Experience from a Case Study, International Journal of Information Management, 16(3), (1996) 205-217.

33. B. Hochstrasser and Griffiths, C. Controlling IT Investment: Strategy and Management, $1^{\text {st }}$ Ed, Chapman and Hall, London (1991).

34. P.E.D. Love, Irani, Z., Standing, C., Lin, C. and Burn, J. The Enigma of Evaluation: Benefits, Costs and Risks of IT in Small-Medium Sized Enterprises, Information and Management, 42(7), (2005) 947-964.

35. M.M. Parker, Benson, R. J. and Trainor, H. E. Information Economics: Linking Business Performance to Information Technology. New Jersey, Prentice-Hall (1988).

36. B. Hochstrasser, Justifying IT Investments. In L. Willcocks (Ed.), Information Management: The Evaluation of Information Systems Investments (Ch 8, pp. 151-169). Chapman and Hall, London (1994).

37. B. Farbey, Land, F., and Targett, D. Evaluating investments in IT. Journal of Information Technology, 7, (1992) 109-122.

38. L. Willcocks, Evaluating Information Technology Investments: Research Findings and Reappraisal, Journal of Information Systems, 2, (1992) 243-268.

39. C. Lin, Huang, Y., Cheng, M., and Lin, W. Effects of Information Technology Maturity on the Adoption of Investment Evaluation Methodologies: A Survey of Large Australian Organizations, International Journal of Management, 24(4), (2007) 697-711.

40. W. Lin, Huang, Y., and Lin, C. Information Technology Executives' View on the Factors that Influence the Success of Information Technology Investments, The Journal of Human Resource and Adult Learning, 3(1), (2007) 41-52.

41. J. Ward and Griffiths, P. Strategic Planning For Information Systems, John Wiley and Sons Ltd, Chichester, UK (1996).

42. J. Ward, Taylor, P. and Bond, P. Evaluation and Realisation of IS/IT Benefits: An Empirical Study of Current Practice, European Journal of Information Systems, 4, (1996) 214-225. 
43. B. Farbey, F. Land, F, and Targett, D. The Moving Staircase: Problems of Appraisal and Evaluation in a Turbulent Environment. Information Technology and People, 12(3), (1999) 238-252.

44. P.P. Tallon, Kraemer, K. L. and Gurbaxani, V. Executives' Perceptions of the Business Value of Information Technology: A Process-Oriented Approach, Journal of Management Information Systems, 16(4), (2000) 145-173.

45. M.J. Earl Putting IT in Its Place: A Polemic for the Nineties, Journal of Information Technology, 7, (1992) 100-108.

46. J. Ward and Murray, P. Benefits Management: Best Practice Guidelines, ISRC-BM-97016, Information Systems Research Centre, Cranfield School of Management, Cranfield, UK (1997).

47. B. Kaplan and Shaw, N. People, organizational and social issues: evaluation as an Exemplar, in: R. Haux, C. Kulikowski (Eds.), Yearbook of Medical Infomatics, (2002) 91-102.

48. M.M. Yusof, Papazafeiropoulou, A., Paul, R. J., and Stergioulas, L. K. Investigating Evaluation Frameworks for Health Information Systems, International Journal of Medical Informatics, 77, (2008) 377-385.

49. C.P. Friedman and Wyatt, J. C. Evaluation Methods in Medical Informatics, Springer-Verlag, New York, USA (1997).

50. K.A. Kuhn, Giuse, D. A., and Talmon, J. L. The Heidelberg Conference: Setting an Agenda for the IMIA Working Group on Health Information Systems, International Journal of Medical Informatics, 69(2-3), (2003) 77-82.

51. C. Lin, Pervan, G., Lin, H-C, and Tsao, H. An Investigation into Business-to-Business Electronic Commerce Organizations, Journal of Research and Practices in Information Technology, 40(1), (2008) 3-18.

52. M.M. Yusof, Kuljis, J., Papazafeiropoulou, A., and Stergioulas, L. K. An Evaluation Framework for Health Information Systems: Human, Organization and Technology-fit Factors (HOT-fit), International Journal of Medical Informatics, 77(6), (2008) 386-398.
53. E. Ammenwerth, Brender, J., Nykanen, P., Prokosch, H. U., Rigby, M., andTalmon, J. HIS-EVAL workshop participants. Visions and strategies to improve evaluation of health information systems: reflections and lessons based on the HIS-EVAL workshop in Innsbruck., International Journal of Medical Informatics, 73(6), (2004) 479-491.

54. J.Y. Liu, Chen, H., Chen, C., and Sheu, T. S. Relationships among Interpersonal Conflict, Requirements Uncertainty, and Software Project Performance, International Journal of Project Management, 29(5), (2011) 547-556.

55. D.P. Lorence and Spink, A. Healthcare Information Systems Outsourcing, International Journal of Information Management, 24(2), (2004) 131-145.

56. C. Lin, Pervan, G., and Mcdermid, D. Issues and recommendations in evaluating and managing the benefits of public sector IT outsourcing. Information Technology and People, 20(2), (2007) 161-183.

57. L. Willcocks and Lester, S. Assessing IT Productivity: Any Way Out of the Labyrinth?, In Willcocks, L., Feeny, D.F. and Islei, G. (Eds.), Managing IT as a Strategic Resource, Ch4, The McGraw-Hill Company, London, 64-93 (1997).

58. R. McIvor, A practical framework for understanding the outsourcing process. Supply Chain Management: An International Journal, 5, (2000) 22-36.

59. R.B. Misra, Global IT Outsourcing: Metrics for Success of All Parties, Journal of Information Technology Cases and Applications, 6(3), (2004) 21-34.

60. D. Haley, A Case for Outsourcing Medical Device Reprocessing, AORN Journal, 79, (2004) 806-808.

61. C. Hsiao, Pai, J., and Chiu, H. The Study on the Outsourcing of Taiwan's Hospitals: A Questionnaire Survey Research, BMC Health Services Research, 9(7) (2009) 8.

62. C. Lin, Lin, K., Huang, Y., and Liu, Y. A Comparative Study of IT Outsourcing Management in Australia and Taiwan, Journal of International Management Studies, 2(2), (2007) 29-39. 
63. X. Liu, Hotchkiss, D. R., and Bose, S. The Effectiveness of Contracting out Primary Health Care Services in Developing Countries: A Review of the Evidence. Health Policy and Planning, 23, (2008) 1-13.

64. N. Menachemi, Burke, D., and Diana, M. Characteristics of Hospitals that Outsource Information. System Functions. Journal of Healthcare Information Management, 19(1), (2007) 63-69.

65. S.J. Moschuris and Kondylis, M. N. Outsourcing in Public Hospitals: A Greek Perspective. Journal of Health Organization and Management, 20(1), (2006) 4-14.

66. S. Meyers, ED Outsourcing: Is It Good for Patient Care?, Trustee, 57, (2004) 12-14.

67. K. Ondo and Smith, M. Outside IT the Case for Full IT Outsourcing: Study Findings Indicate Many Hospitals Are Turning to Full IT Outsourcing to Achieve IT Excellence. What's the Best Approach for Your Organization?, Healthcare Financial Management, February, (2006) 1-3.

68. V. Roberts, Managing Strategic Outsourcing in the Healthcare Industry. Journal of Healthcare Management, 46(4), (2001) 239-249.

69. J.S. Hsu, Lin, T., Zheng, G., and Hung, Y. Users as knowledge co-producers in the information system development project, International Journal of Project Management, 30(1), (2012) 27-36.

70. G.J. Browne and Ramesh, V. Improving Information Requirements Determination: A Cognitive Perspective, Information and Management, 39, (2002) 625-645.

71. T. Gorschek, Svahnberg, M., Borg, A., Loconsole, A., and Sandahl, K. A controlled empirical evaluation of a requirements abstraction model, Information and Software Technology, 49(7), (2007) 790-805.

72. C. Lin and Lin, K. A Study of Information Requirement Determination Process of an Executive Information System, In Information Resources Management Association, USA (Ed.), Enterprise Information Systems: Concepts, Methodologies, Tools and Applications, IGI Publishing, Hershey, USA, (2011) 1030-1038.

73. C. Urquhart Analysts and Clients in Organizational Context: A Conversational Perspective, Journal of
Strategic Information Systems, 10, (2001) 243-262.

74. O.E.M. Khalil and Elkordy, M. M. EIS Information: Use and Quality Determination, Information Resources Management Journal, 18(2), (2005) 68-93.

75. F. Land, Adapting to Changing User Requirements, In Galliers, R.D. (Ed.), Information Analysis: Selected Readings, Ch. 12, Addison - Wesley, Sydney (1987).

76. R.D. Galliers and Sutherland, A. R. Information Systems Management and Strategy Formulation: The 'Stages of Growth' Model Revisited, Journal of Information Systems, 1, (1991) 89-114.

77. L. Bhabuta, Sustaining Productivity and Competitiveness by Marshalling IT in Information Technology Management for Productivity and Strategic Advantage. Proceedings of the IFIP TC8 Open Conference, Singapore (1988).

78. R. Hirschheim, Earl, M., Feeny, D. and Lockett, M. An Exploration Into the Management of the Information Function: Key issues and an Evolutionary Model, Proceedings of Information Technology Management for Productivity and Strategic Advantage, IFIP TC-8 Open Conference, Singapore, March (1988).

79. R.L. Nolan Managing the Crises in Data Processing, Harvard Business Review, March-April, (1979) 115-126.

80. M.M. Parker, Strategic Transformation and Information Technology, Prentice-Hall, Upper Saddle River, New Jersey (1996).

81. A.A. Yayla and Hu, Q. The impact of IT-business strategic alignment on firm performance in a developing country setting: exploring moderating roles of environmental uncertainty and strategic orientation, European Journal of Information Systems, 21(4), (2011) 373-387.

82. J.J. Li. The alignment between organizational control mechanisms and outsourcing strategies: A commentary essay, Journal of Business Research, 65(9), (2012) 13841386.

83. E.D. Hahn and Bunyaratavej, K. Services cultural alignment in offshoring: The impact of cultural dimensions on offshoring location choices, Journal of 
Operations Management, 28(3), (2010) 186 -193.

84. D.A. Ralston, Holt, D.H., Terpstra, R.H., and Kai-Cheng, Y. The impact of national culture and economic ideology on managerial work values: a study of the United States, Russia, Japan, and China. Journal of International Business Studies, 39(1), (2008) 8-26.

85. G.H. Hofstede Cultures and organizations: Software of the mind. New York, NY: McGraw-Hill (1997).

86. J. Han and Lee, S. T. Impact of Vendor Selection on Firms' IT Outsourcing: The Korea Experience, Journal of Global Information Management, 20(2), (2012) 25-43.

87. C.W. Choo, Information management for the intelligent organization: the art of scanning the environment. (3rd ed.). Medford: Information Today, Inc (2001).

88. M. Bensaou and Venkatraman, N. Inter-organizational relationships and information technology: a conceptual synthesis and a research framework. European Journal of Information Systems, 5(2), (1996) 84-91.

89. J.W. Mullins and Sutherland, D. J. New product development in rapidly changing markets: An exploratory study. Journal of Product Innovation Management, 15(3), (1998) 224-236.

90. A.H. Van de Ven, Delbecq, A. L., and Koenig, R. Determinants of coordination modes within organizations. American Sociological Review, 41(2), (1976) 322-338.

91. R.B. Duncan, Characteristics of organizational environments and perceived environmental uncertainty. Administrative Science Quarterly, 17(3), (1972) 313-327.

92. M. Li and Ye, L. R. Information technology and firm performance: linking with environmental, strategic and managerial contexts. Information and Management, 35(1), (1999) 43-51.

93. E.T.G. Wang Effect of the fit between information processing requirements and capacity on organizational performance. International Journal of Information Management, 23(3), (2003) 239-247.

94. R.L. Daft and Lengel, R. H. Organizational information requirements: media richness and structural design. Management Science, 32(5), (1986) 554-571.
95. J.R. Galbraith, Organization Design. Reading: AddisionWesley (1977).

96. A.N. Licht, Legal plug-Ins: Cultural distance, crosslisting, and corporate governance reform. Berkeley Journal of International Law, 22, (2004) 195-239.

97. M.L. Tushman and Nadler, D. A. Information processing as an integrating concept in organizational design. Academy of Management Review, 3(3), (1978) 613-624.

98. K.M. Gilley and Rasheed, A. Making more by doing less: analysis of outsourcing and its effects on firm performance. Journal of Management, 26(4), (2000) 763-790.

99. K.L. McLellan, Marcolin, B. L., and Beamish, P. W. Financial and Strategic Motivations Behind IS Outsourcing. Journal of Information Technology, 10(4), (1995) 299-321.

100. M. Chan, Pang, V., Bunker, D., and Smith, S. What Do We Mean by E-Procurement?-A Private Hospital Perspective in Australia, The Tenth Pacific Asia Conference on Information Systems (PACIS 2006), Kuala Lumpur, Malaysia, July 6-9, (2006), pp1353-1361.

101. Australian Bureau of Statistics, Australian Bureau of Statistics: Business Use of Information Technology, 2008-09, Canberra, Australia (2010).

102. E. More and McGrath, M. An Australian Case in eHealth Communication and Change, The Journal of Management Development, 21(7/8), (2002) 612-632.

103. GS1, Australia Hospital Pharmaceutical eCommerce Looks Healthy, Media Press Release, December, GS1 Australia, Australia (2005).

104. NEHTA, Australia Launches Leading Edge e-Health Supply Chain Location Directory - NEHTA, National EHealth Transition Authority, Media Press Release, [Online] http://www.nehta.gov.au/, Australia (2010).

105. M. Lee, and Jones, A. M. How Did Dentists Respond to the Introduction of Global Budgets in Taiwan? An Evaluation Using Individual Panel Data, International Journal of Health Care Finance and Economics. 4(4), (2004) 307326. 
106. C. Lin, Huang, Y., and Jalleh, G. Improving Alliance Satisfaction: The Resource Alignment of IT Competency in Small Healthcare Centers, International Technology Management Review, November, 1(2), (2008) 25-42.

107. D. Shapiro, Examining Taiwan's hospitals, Topics, American Chamber of Commerce in Taipei, 39(3) (2009).

108. THRF, Hospital Finance: The Financial Supervision for the Health Institutions in Taiwan, Taiwan Healthcare Reform Foundation, Taipei Taiwan (2011).

109. K.M. Eisenhardt Building Theories From Case Study Research, Academy of Management Review, 14(4), (1989) 532-550.

110. D. Silverman, Interpreting qualitative data (2nd ed.). London: Sage (2001).

111. M.B. Miles and Huberman, A.M. Qualitative Data Analysis: An Expanded Sourcebook, Sage Publications, California (1994).

112. R.K. Yin, Case Study Research, Design and Methods, $3^{\text {rd }}$ Ed., Newbury Park, Sage Publications (2002).

113. H.K. Klein and Myers, M. D. A Set of Principles for Conducting and Evaluating Interpretive Field Studies in Information Systems, MIS Quarterly, 23(1), (1999) 67-

94.

114. K. Lin, Lin, C. and Tsao, H. IS/IT Investment Evaluation and Benefit Realization Practices in Taiwanese SMEs, Journal of Information Science and Technology, 2(4), (2005) 44-71.

115. J. He and King, W.R. The role of user participation in information systems development: implications from a meta-analysis. Journal of Management Information Systems, 25(1), (2008) 301-331.

116. R.T. Nakatsu and Iacovou, C. L. A Comparative Study of Important Risk Factors Involved in Offshore and Domestic Outsourcing of Software Development Projects: A Two-Panel Delphi Study, Information and Management, 46, (2009) 57-68.

117. C. Lin, Pervan, G., and McDermid, D. IS/IT Investment Evaluation and Benefits Realization Issues in Australia, Journal of Research and Practices in Information Technology, 37(3), (2005) 235-251.
118. S.M. Mudambi and Tallman, S. Make, buy or ally? Theoretical perspectives on knowledge process outsourcing through alliances, Journal of Management Studies, 47(8), (2010) 1434-1456.

119. C. Ranganathan and Balaji, S. Critical capabilities for offshore outsourcing of IS. MIS Quarterly Executive, 6(3), (2007) 147-164.

120. P. Weill, The Role and Value of Information Technology Infrastructure: Some Empirical Observations. In R. Banker, R. Kauffman and M.A. Mahmood (Eds.), Strategic Information Technology Management: Perspectives on Organizational Growth and Competitve Advantage. Middleton, PA: Idea Group Publishing (1993). 